\title{
ANALISIS KEUNTUNGAN USAHA "SARABA" DI RUMAH MAKAN STEVANNY DI KAWASAN BOULEVARD KOTA MANADO
}

\author{
Priscilia Indriani Runturambi \\ Ribka Magdalena Kumaat \\ Juliana Ruth Mandei
}

\begin{abstract}
This study aims to analyze the profit received by the owner, producer and seller of the business "Saraba" in "Stevanny Restaurant" in the Boulevard Area of Manado City. This research was conducted from July to September 2018. This study used primary data and secondary data. Primary data was obtained by using interview techniques directly to the owner of the restaurant. Secondary data in this study comes from books available at local bookstores in Manado City, the internet such as google scholar to access articles from various scientific journals and theses from other universities which was related to profit analysis. Data collected in this study are presented in table form and then described and analyzed using the profit analysis formula. The results showed that the profits obtained in one month of the production process in September 2019, which is for 30 days where every day one production process is carried out so 30 days the production process is carried out by the businessman "Saraba" in "Stevanny's Restaurant" in the Boulevard Area of Manado City for Rp. 5,609,481 per month. ${ }^{\text {sjind } d \text { eprm* }}$
\end{abstract}

Keywords: profit analysis, saraba, Stevanny restaurant, the Boulevard Area of Manado City

ABSTRAK

Penelitian ini bertujuan untuk menganalisis keuntungan yang diterima oleh pemilik, produsen sekaligus penjual usaha "Saraba" di "Rumah Makan Stevanny" di Kawasan Boulevard Kota Manado. Penelitian ini dilakukan dari bulan Juli sampai bulan September 2018 di rumah makan Stevanny di kawasan Boulevard Kota Manado. Penelitian ini menggunakan data primer dan data sekunder. Data primer diperoleh dengan mengunakan teknik wawancara langsung kepada pemilik (owner) usaha "Saraba" di rumah makan Stevanny. Data sekunder dalam penelitian ini bersumber dari buku yang tersedia di toko buku lokal, internet seperti google cendekia untuk mengakses artikel dari berbagai jurnal ilmiah dan skripsi dari perguruan tinggi lain yang berkaitan dengan analisis keuntungan. Data yang dikumpulkan dalam penelitian ini disajikan dalam bentuk tabel kemudian dideskripsikan dan dianalisis dengan menggunakan rumus analisis keuntungan. Hasil penelitian menunjukkan bahwa keuntungan yang diperoleh dalam satu bulan proses produksi pada bulan September 2019, yaitu selama 30 hari dimana setiap satu hari dilakukan satu kali proses produksi jadi dalam 30 hari dilakukan 30 kali proses produksi oleh pengusaha "Saraba" di "Rumah Makan Stevanny" di Kawasan Boulevard Kota Manado sebesar Rp.5.609.481 per bulan. "jikkteprm*.

Kata kunci: analisis keuntungan, saraba, rumah makan Stevanny, Kawasan Boulevard Kota Manado.

\section{PENDAHULUAN}

\section{Latar Belakang}

Indonesia merupakan salah satu negara yang memiliki jumlah penduduk yang cukup besar dan menyimpan banyak potensi, salah satunya adalah potensi bisnis hasil pertanian dimana sebagian besar penduduk menguntungkan hidupnya pada dunia usaha kecil maupun besar. Saat ini potensi hasil pertanian sudah banyak yang memanfaatkan serta mengelolahnya. Jahe merupakan salah satu bahan olahan rempah-rempah hasil pertanian yang sudah banyak digunakan dalam dunia perindustrian dan bisnis perdagangan.
Jahe merupakan tanaman obat berupa tumbuhan rumpun berbatang semu. Di Indonesia jahe termasuk tanaman yang sangat populer, baik itu sebagai obat herbal maupun sebagai bumbu penyedap masakan. Tanaman jahe terbagi menjadi tiga yaitu jahe merah, jahe putih dan jahe gajah. Namun, jenis jahe yang paling diakui khasiat obatnya adalah jahe merah dan jahe putih (Lentera, 2002).

Usaha kuliner atau rumah makanan di Kota Manado sedang mengalami perkembangan yang relatif pesat. Perkembangan yang pesat ini menyebabkan semakin banyak orang tertarik untuk menjalankan usaha. 
Kawasan Boulevard yang terletak di sepanjang jalan Pierre Tendean Kota Manado merupakan pusat keramaian Kota Manado lokasinya sangat strategis dan telah menjadi daya tarik baru bagi penduduk setempat. Pemerintah daerah menamakannya sebagai kawasan B on B (Boulevard on Business). Kawasan ini menjadi tempat bisnis teramai di Kota Manado baik dari sektor usaha formal maupun informal.

Bisnis minuman "Saraba" merupakan usaha formal dan salah satu usaha yang ramai dikunjungi di kawasan Boulevard Kota Manado. Berdasarkan hasil survey, dikawasan ini tercatat terdapat 8 rumah makan yang aktiv menjual produk yang sama yaitu "Saraba". Rumah makan Stevanny merupakan salah satu rumah makan yang aktiv menjual "Saraba" di kawasan Boulevard Kota Manado yang terlihat ramai dan menguntungkan. Berdasarkan hasil wawancara dengan pemilik rumah makan Stevanny, menyebutkan bahwa rumah makan Stevanny merupakan satu-satunya rumah makan dengan status bangunan milik sendiri.

Selain menu ciri khas "Saraba" di rumah makan Stevanny ada juga beberapa produk lain yang di tawarkan yaitu kopi susu, pisang goreng, nasi goreng, dan milu siram. Berdasarkan hasil wawancara, usaha "Saraba" menghasilkan kontribusi paling besar dibandingkan dengan menu lainnya, dengan dengan jumlah penerimaan sebesar $60 \%$ dibandingkan dengan menu lainnya hanya memperoleh $40 \%$, hal ini dikarenakan menu lainnya banyak dijumpai di pasaran.

Meningkatnya jumlah usaha kuliner atau makanan akan meningkatkan tingkat persaingan diantara rumah makan, khususnya rumah makan yang menghidangkan produk kuliner yang sejenis (Masengi, 2014).

Pemilik saraba tidak hanya sekedar sebagai pemilik tetapi juga terlibat dalam proses produksi sampai dengan berperan melayani pelanggan. Hal ini menunjukan aktivitas produksi dan penjualan merupakan cerminan kegiatan ekonomi yang tidak dapat berdiri sendiri tetapi senantiasa menunjukkan adanya saling ketergantungan pedagang dan tenaga kerja.

Adapun uraian di atas dijelaskan yakni yang di utamakan keberhasilan setiap usaha tidak selamanya berjalan dengan baik dan berbeda-beda, persaingan yang ketat, dan terlihat juga adanya saling ketergantungan pedagang dan tenaga kerja. Selama ini belum ada suatu analisis tentang usaha "Saraba" khusus rumah makan Stevanny tentang besarnya keuntungan "Saraba". Maka dengan ini penulis ingin menganalisis secara lebih dalam bagaimana keuntungan yang di dapatkan pedagang usaha "Saraba" rumah makan Stevanny di Kawasan kuliner di Boulevard Kota Manado.

\section{Rumusan Masalah}

Adapun yang menjadi rumusan masalah adalah Bagaimana besarnya keuntungan terhadap usaha "Saraba" di rumah makan Stevanny di Kawasan Boulevard Kota Manado.

\section{Tujuan Penelitian}

Tujuan dari penulisan ini adalah untuk menganalisis besarnya keuntungan terhadap pedagang usaha "Saraba" di Rumah makan Stevanny di Kawasan Boulevard Manado.

\section{Manfaat Penelitian}

Penelitian ini diharapkan dapat menjadi gambaran untuk mengetahui keuntungan yang didapatkan dan penelitian ini diharapkan dapat menjadi tambahan wawasan, dan pengetahuan dalam usaha Saraba.

\section{METODE PENELITIAN}

\section{Waktu dan Lokasi}

Penelitian akan dilaksanakan selama tiga bulan dari persiapan sampai penyusunan laporan yakni bulan Juli sampai bulan September Tahun 2018 yang berlokasi di usaha rumah makan Stevanny di Kawasan Boulevard Kota Manado mulai dari tahap persiapan proposal sampai dengan penyusunan laporan penelitian.

\section{Metode Pengumpulan Data}

Metode yang digunakan dalam penelitian ini adalah metode studi kasus. Data yang digunakan dalam penelitian ini adalah data primer dan data sekunder. Data primer diperoleh dengan mengunakan teknik wawancara langsung kepada pemilik (owner) usaha "Saraba" dirumah makan Stevanny dengan menggunakan daftar pertanyaan (kuesioner) sebagai alat bantu dalam pengumpulan data dan diisi oleh peneliti. Sedangkan data sekunder dalam penelitian ini bersumber dari internet, perpustakaan serta literatur dari berbagai sumber seperti jurnal ilmiah dan penelitian terdahulu terkait dengan analisis keuntungan. Responden dalam penelitian ini hanya terdiri dari pemilik usaha rumah makan Stevanny.

\section{Konsep Pengukuran Variabel}

Variabel dalam penelitian ini adalah sebagai berikut:

1. Produksi yaitu jumlah produksi dari dalam satu kali proses produksi.

2. Harga jual minuman saraba yang di sediakan pada setiap hari kemudian di jumlahkan dalam satu bulan (Rp/gelas) 
3. Biaya Produksi yaitu seluruh biaya yang dikeluarkan dalam proses olahan saraba pada setiap kali produksi. Untuk menghitung biaya produksi digunakan rumus matematis dibawah ini

Keterangan:

$$
\mathbf{T C}=\mathbf{F C}+\mathrm{VC}
$$

$\mathrm{TC}=$ Biaya Total

$\mathrm{FC}=$ Biaya Tetap

$\mathrm{VC}=$ Biaya Variabel

Biaya produksi diukur dalam satuan rupiah (Rp/bulan) terdiri dari:

A. Biaya Tetap yaitu biaya yang besar kecilnya tidak bergantung pada volume produksi diukur dalam satuan rupiah (Rp/bulan)

1) Biaya penyusutan alat (mesin) yaitu nilai penyusutan yang penggunaannya tidak habis dalam satu masa produksi. Biaya penyusutan alat terdiri :

\section{a. Kompor gas}

b. Tabung gas

c. Gelas Royallex

d. Loyang

e. Panci $15 \mathrm{Kg}$

f. Panci saucepan

g. Saringan bulat

h. Spatula kayu

i. Sendok

j. Pisau

k. Piring tatakan gelas

1. Kursi plastic

m. Meja

n. Lemari piring

2) Biaya Listrik(Rp/bulan)

3) Pajak (Rp/Bulan)

4) Biaya Retribusi (Rp/bulan)

B. Biaya Variabael yaitu biaya yang berhubungan langsung dengan jumlah produksi dihitung dalam satuan rupiah (Rp/bulan).

1) Biaya Tenaga kerja yaitu banyaknya tenaga kerja yang dicurahkan dalam proses produksi selama jam kerja terdiri dari 2 tenaga kerja dari luar keluarga 1 tenaga kerja dari dalam keluarga dan diukur dalam satuan (Rp/bulan)

2) Biaya Bahan Baku (Rp/bulan)
a. Air (Liter)
b. Jahe merah dihitung dalam satuan $(\mathrm{Kg})$
c. Gula aren dihitung per batu (Rp)
d. Sereh dihitung dalam satuan $(\mathrm{Rp})$
e. Susu dihitung per kaleng (Rp)
3) Biaya transportasi (Rp/bulan)
4) Biaya Bahan Bakar (Rp/Bulan)

4. Penerimaan yaitu perkalian antara jumlah produksi yang didapat dengan harga jual atau pendapatan kotor yang dinyatakan dalam rupiah (Rp/bulan).

Berikut rumus untuk menghitung penerimaan.

$$
\mathbf{T R}=\mathbf{P} \times \mathbf{Q}
$$

Keterangan:

$$
\begin{aligned}
& \mathrm{TR}=\text { Total Revenue } \text { (Total Penerimaan) } \\
& \mathrm{P}=\text { Price } \text { (Harga) } \\
& \mathrm{Q}=\text { Quantity (Jumlah yang diproduksi) }
\end{aligned}
$$

5. Keuntungan yaitu nilai yang diperoleh dari hasil penjualan saraba dikurangi dengan biaya yang dikeluarkan atau sebagai laba bersih yang dinyatakan dalam rupiah (Rp/bulan).

\section{Analisis Data}

Analisis data yang digunakan dalam penelitian ini yaitu analisis deskriptif dan akan dibuat dalam bentuk tabel. Untuk mengetahui besarnya keuntungan bersih pada usaha "Saraba" dirumah makan Stevanny di kawasan Boulevard Kota Manado yaitu dengan menggunakan analisis keuntungan dengan rumus:

$$
\boldsymbol{\pi}=\mathbf{T R}-\mathbf{T C}
$$

Dimana:

$$
\begin{aligned}
& \pi=\text { Income / Keuntungan usaha saraba jahe }(\mathrm{Rp}) \\
& \mathrm{TR}=\text { Total Revenue / Total penerimaan }(\mathrm{Rp}) \\
& \mathrm{TC}=\text { Total Cost } / \text { Total biaya produksi }(\mathrm{Rp})
\end{aligned}
$$

\section{HASIL DAN PEMBAHASAN}

\section{Deskripsi Objek Penelitian}

\section{Sejarah Dan Perkembangan Usaha Saraba Jahe Dikawasan Boulevard Kota Manado}

Sejarah terbentuknya Usaha "Saraba" di Kawasan Boulevard Kota Manado dimulai pada Bulan Juni tahun 1986 oleh bapak Latada yang berdomisilih di Jl. Piere Tendean, Kelurahan Titiwungen Selatan Kecamatan Sario. Usaha Meubel dan jagung bakar menjadi awal usaha bapak Latada. Namun, usaha meubel dan jagung bakar tidak bertahan lama di karenakan tidak menjanjikan dan kurangnya pelanggan. Berjalannya waktu dan perkembangan, selang 3 bulan kemudian dengan bermodalkan uang Rp.300.000 sang pemilik yaitu Bapak Latada memulai usaha yang baru yaitu menjual minuman Saraba. Usaha minuman Saraba cukup menjanjikan dan sampai saat ini dibilang cukup populer. Semakin banyaknya permintaan sejak saat itu, sehingga saat itu beberapa warga satu per satu mengkuti jejak usaha bapak Latada yaitu menjual Saraba.

\section{Kondisi Usaha "Saraba" Di Rumah Makan Stevanny Di Kawasan Boulevard Kota Manado Operasional usaha berjalan selama 30 hari dengan jam operasional selama 14 jam per hari, dimulai pada jam 14.00 sampai dengan penjualan saraba terjual, dengan batas waktu sampai jam 05.00 pagi. Usaha Saraba dijalankan oleh 5 orang tenaga kerja yaitu tenaga kerja dari dalam keluarga terdiri dari 3 tenaga kerja dan tenaga kerja dari luar keluarga terdiri dari 2 tenaga kerja.}


Dalam menjalankan usaha ini, jumlah yang terjual setiap hari kurang lebih 55 gelas per hari, sehingga total omzet (penerimaan kotor) khusus untuk penjualan "Saraba" di Rumah makan Stevany di Kawasan Boulevard Kota Manado adalah sebesar Rp.16.500.000 per bulan. Usaha ini dianggap sebagai kegiatan ekonomi yang berkesinambungan dan secara kuantitas mampu menjamin pemenuhan kebutuhan hidup bagi pemilik beserta keluarganya.

\section{Biaya Produksi}

Biaya produksi adalah biaya yang dikeluarkan perusahaan dalam proses dari jahe menjadi Saraba. Usaha Saraba di rumah makan Stevanny di Kawasan Boulevard Kota Manado mengeluarkan biaya-biaya yang diperlukan dalam satu tahun proses produksi yang berasal dari modal sendiri. Biaya produksi pembuatan Saraba dibagi atas biaya tetap dan biaya variable.

\section{Biaya Tetap}

Biaya tetap adalah biaya yang dikeluarkan untuk kegiatan usaha yang jumlahnya relatif tetap tidak bergantung kepada besar kecilnya produksi. Yang tergolong biaya tetap adalah biaya penyusutan alat bangunan dan pajak, biaya tersebut tetap dikeluarkan meskipun produksi terhenti.

1. Biaya Penyusutan Peralatan

Biaya penyusutan alat merupakan biaya pengurangan nilai yang disebabkan oleh pemakaian alat selama proses berlangsung. Penyusutan yang dihitung adalah umur teknis alat berdasarkan pemakaian alat-alat produksi milik sendiri.

Biaya penyusutan peralatan dihitung dengan cara membagi biaya awal peralatan dengan lama pemakaian masing-masing peralatan.

Dapat dilihat dengan rumus di bawah ini

$$
\mathbf{P}=(\mathbf{H A}-\mathbf{H B}) / \mathbf{T}
$$

Dimana:

$$
\begin{aligned}
& \mathrm{P}=\text { Biaya Penyusutan alat } \\
& \mathrm{HA}=\text { Harga Awal } \\
& \mathrm{HB}=\text { Harga Akhir } \\
& \mathrm{T}=\text { Umur ekonomis alat }
\end{aligned}
$$

Besarnya biaya penyusutan peralatan yang di keluarkan oleh penjual usaha "Saraba" di rumah makan Stevanny di Kawasan Boulevard Kota Manado dapat dilihat Tabel 1.

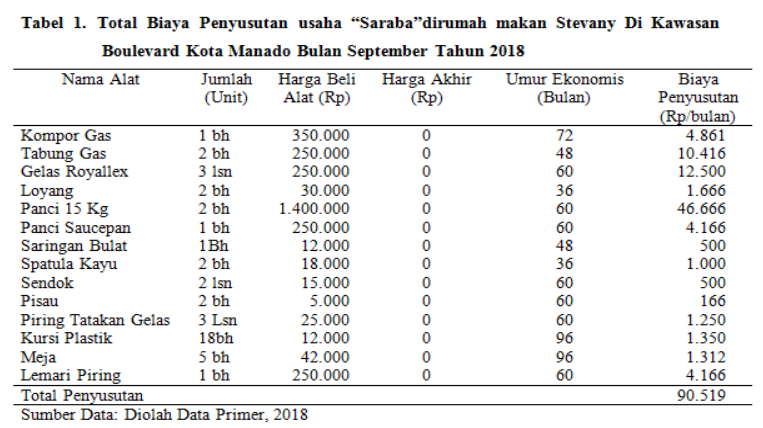

Berdasarkan Tabel 1, biaya penyusutan peralatan penjual Usaha "Saraba" rumah makan Stevany di Kawasan Boulevard Kota Manado yang terkecil adalah Rp.166 dan biaya penyusutan terbesar Rp.46.666.

Biaya penyusutan khusus kursi dan meja sudah dikurangi 60 persen dari penerimaan usaha "Saraba" dan berdasarkan pemakaian meja dan kursi tidak hanya menu "Saraba" tetapi ada menu lainnya.

2. Biaya Listrik

Pedagang Usaha "Saraba" di rumah makan Stevanny di Kawasan Boulevard Kota Manado mengeluarkan biaya listrik setiap bulan untuk listrik air, dan 2 buah lampu untuk dapur dan ruang tempat minum saraba. Biaya listrik yang dikeluarkan oleh pedagang rumah makan Stevanny adalah Rp.100.000 per bulan. Biaya yang dibayar Listrik khusus usaha Saraba yaitu $60 \%$ berdasarkan hasil penjualan produksi saraba di bandingkan dengan penerimaan produksi menu lainnya. Adapun Biaya Listrik yang di keluarkan khusus usaha "Saraba" rumah makan Stevanny adalah Rp.60.000 per bulan, sedangkan sisanya dibayar dari hasil beberapa menu tambahan dirumah makan Stevanny dikawasan Boulevard Kota Manado.

3. Pajak

Usaha rumah makan Stevanny setiap bulan wajib membayar, menghitung, dan melaporkan pajak yang terutang dari hasil penjualan. Berdasarkan hasil penelitian usaha Saraba dirumah makan Stevanny mendapatkan hasil penjualan sebesar Rp.16.500.000 /bulan maka usaha Saraba wajib membayar sebesar 10\% pajak daerah sebesar Rp.1.650.000 perbulan.

4. Biaya Retribusi

Sebagai usaha yang ramai di kawasan Boulevard Kota Manado, di Rumah Makan Stevanny selalu membayar biaya pungutan atau retribusi untuk kelancaran usahanya. Retribusi yang dikenakan yaitu retribusi jasa umum atau retribusi pelayanan persampahan dan kebersihan. Retribusi atau pungutan yang dikeluarkan responden berjumlah Rp.50.000. Biaya tersebutdikurangi biaya 60 persen dari hasil penjulan saraba, biaya retrebusi dibayardengan jumlah Rp.30.000/ bulan.

Adapun biaya retribusi yang dikeluarkan oleh penjual Usaha "Saraba"dirumah makan Stevanny di Kawasan Boulevard Kota Manado tergantung kepada jumlah penerimaan. Biaya retribusi yang dikenakan kepada pedagang yakni Rp.30.000/bulan.

Tabel 2. Rekapitulasi Total Biaya Tetapusaha "Saraba" di Rumah Makan Stevanny di Kawasan Boulevard Kota Manado Bulan September Tahun 2018

\begin{tabular}{llr}
\hline No & Uraian Biaya Tetap & Total Biaya \\
\hline 1 & Biaya Penyusutan & 90.519 \\
2 & Biaya Lisrrik & 60.000 \\
3 & Pajak & 1.650 .000 \\
3 & Biaya Retrebusi & 30.000 \\
\hline & Total produksi biaya tetap & 1.830 .519 \\
\hline Sumber: & Diolah Data Primer, 2018
\end{tabular}

Sumber: Diolah Data Primer, 2018 


\section{Biaya Variabel}

Biaya variabel adalah biaya yang nilainya bergantung pada nilai atau jumlah produksi menu yang dihasilkan atau terjual. Yang tergolong biaya variabel adalah biaya pembelian bahan baku makanan dan minuman, biaya transportasi, biaya bahan bakar dan barang pelengkap lainnya.

1. Biaya Bahan Baku

Biaya bahan baku dalam proses pembuatan saraba meliputi bahan dasar pembuatan saraba serta bumbu tambahan yang digunakan. Berikut rincian biaya bahan yang digunakan dalam 1 kali proses produksi dengan menghasilkan 55 gelas saraba siap jual.

\begin{tabular}{|c|c|c|c|c|c|}
\hline $\begin{array}{r}\text { Bahan } \\
\text { Baku }\end{array}$ & $\begin{array}{c}\text { Jumlah } \\
\text { Pemakaian } \\
(\text { /Hari })\end{array}$ & $\begin{array}{l}\text { Satuan } \\
\text { (Unit) }\end{array}$ & $\begin{array}{c}\text { Harga Beli } \\
\text { (Rp/Satuan) }\end{array}$ & $\begin{array}{c}\text { Biaya Bahan } \\
\text { baku } \\
\text { (Rp/Hari) }\end{array}$ & $\begin{array}{l}\text { Total Biaya } \\
\text { (Rp/Bulan }\end{array}$ \\
\hline Air & 27,5 & Liter & 5.000 & 8.000 & 240.000 \\
\hline Jahe Merah & 3 & $\mathrm{Kg}$ & 15.000 & 45.000 & 1.350 .000 \\
\hline Gula Aren & 4 & $\mathrm{Kg}$ & 11.000 & 44.000 & 1.320 .000 \\
\hline Susu Kaleng & 6 & Kaleng & 9.000 & 54.000 & 1.620 .000 \\
\hline Sereh & 2 & Ikat & 5.000 & 10.000 & 300.000 \\
\hline Garam & 2 & Bungkus & 2.000 & 4.000 & 120.000 \\
\hline Jumlah biaya & bahan baku & & & & 4.950 .0000 \\
\hline
\end{tabular}

Tabel 3 menunjukan bahwa komponen biaya bahan baku pembuatan saraba berupa bahan (Air, jahe merah, sereh, gula aren, susu kaleng, garam), dengan rata-rata biaya bahan baku dalam produksi pembuatan Saraba dirumah makan Stevanny di Kawasan Boulevard Kota Manado adalah sebesar Rp.165.000 per hari atau dalam satu kali produksi dengan menghasikan sebanyak 55 gelas saraba.

2. Biaya Transportasi

Biaya transportasi merupakan biaya yang dikeluarkan oleh pedagang saat transportasi dari pasar ke tempat usaha.Transportasi yang di pakai adalah kendaraan milik sendiri yaitu sepeda motor. Biaya yang di keluarkan yaitu Rp10.000 di peroleh dari harga bensin yaitu 1 liter bensin sama dengan Rp.10.000 dengan pemakaian dua hari per biaya transportasi. Biaya transportasi penjual rumah makan Stevany di Kawasan Boulevard Kota Manado setiap bulan yaitu Rp.150.000.

Adapun total biaya transportasi khusus usaha "Saraba" Rp.90.000 perbulan yaitu hasil dari pengurangan biaya khusus usaha Saraba sebesar 60\% dan biaya sisa menu lainnya sebesar $40 \%$. Biaya sebesar $60 \%$ di peroleh dari biaya dari penerimaan minuman Saraba terbanyak yang diterima di Rumah Makan Stevanny di kawasan Boulevard Kota Manado.

3. Biaya Tenaga Kerja

Penyediaan tenaga kerja merupakan cerminan dari kualitas sumber daya manusia yang ada. Termasuk dalam profesi usaha pembuatan produk kuliner, kualitas tenaga kerja sangat mempengaruhi produktifitas kerja. Dalam proses produksi pembuatan minuman saraba, sebagai suatu struktur dasar aktivitas usaha, tenaga kerja yang digunakan merupakan faktor yang sangat penting.
Tabel 4. Rata-rata Biaya Tenaga Kerja pada Usaha Pembuatan Usaha Saraba di Rumah Makan Stevanny di Kawasan Boulevard Kota Manado Bulan September Tahun 2018

\begin{tabular}{lcccc}
\hline Uraian & Satuan & Jam Kerja & $\begin{array}{c}\text { Biaya Tenaga Kerja } \\
(\text { Rp/Hari })\end{array}$ & $\begin{array}{c}\text { Biaya Tenaga Kerja } \\
\text { (Rp/Bulan) }\end{array}$ \\
\hline Tenaga Kerja & 2 & $14.00-17.00$ & 80.000 & 2.400 .000 \\
Tenaga Kerja & 1 & $17.00-05.00$ & 36.000 & 1.080 .000 \\
\hline \multicolumn{7}{l}{ Jumlah biaya tenaga kerja } \\
\multicolumn{3}{l}{ Sumber: Diolah Data Primer, 2018 }
\end{tabular}

Hasil penelitian ini menunjukan bahwa dalam usaha pembuatan minuman hangat saraba, menggunakan 5 orang tenaga kerja, termasuk pemilik usaha sendiri yaitu suami dan istri dan tenaga bantuan dari dalam keluarga 1 tenaga kerja dan tenaga dari luar keluarga 2 tenaga kerja, dengan lingkup kerja sejak penyediaan bahan baku sampai proses produksi olahan saraba dengan waktu mulai dari jam 14.00 sampai dengan jam 17.00 dengan biaya pekerjaan terhitung perhari sebesar Rp.40.000 per hari, dan 1 tenaga kerja dari dalam keluarga yaitu sepupu, dengan waktu pekerjaan dari jam 17.00 sore sampai dengan jam 05.00 pagi. Upah tenaga kerja luar keluarga terdiri dari 2 orang sebesar Rp.2.400.000 per bulan, sedangkan upah tenaga kerja dalam keluarga terdiri dari 1 orang sebesar Rp.1.800.000. Biaya upah tenaga kerja dalam keluarga dikurangi biaya $60 \%$ pelayanan diluar penjualan saraba dan penghasilan tenaga kerja khusus penjualan saraba sebesar Rp.1.080.000. Adapun Biaya tenaga kerja yang dikeluarkan sesuai dengan jenis pekerjaan dan jam kerja yang dilakukan.

Setiap harinya pemilik usaha mengeluarkan upah tenaga kerja sebesar Rp.116.000 untuk 3 tenaga kerja, maka setiap bulan biaya yang di keluarkan untuk tenaga kerja khusus yang menjalankan usaha minuman saraba yaitu Rp.3.480.000

4. Biaya Bahan Bakar

Biaya Bahan bakar adalah biaya yang digunakan dalam proses memasak bahan baku menjadi minuman Saraba.Bahan bakar yang di pakai yaitu kompor yang digunakan adalah gas LPG ukuran $3 \mathrm{Kg}$. Usaha "Saraba" dirumah makan Stevanny setiap hari hanya membutuhkan 1 tabung gas. Harga gas pertabung adalah Rp.18.000. Adapun biaya bahan bakar setiap bulan khusus "Saraba” adalah Rp.540.000.

Tabel 5. Rekapitulasi Total Biaya Produksi Usaha Saraba di Rumah Makan Stevanny di Kawasan Boulevard Manado Bulan September Tahun 2018

\begin{tabular}{llr}
\hline No & Uraian & Perbulan \\
\hline & Biaya Variabel & \\
1 & Biaya Bahan Baku & 4.950 .000 \\
2 & Biaya Transportasi & 90.000 \\
3 & Biaya Tenaga Kerja & 3.480 .000 \\
4 & Biaya Bahan Bakar & 540.000 \\
& Biaya Tetap & \\
1 & Biaya Listrik & 60.000 \\
2 & Biaya Retribusi & 30.000 \\
3 & Pajak & 1.650 .000 \\
4 & Biaya Penyusutan & 90.519 \\
\hline & Total Biaya Produksi & 10.890 .519 \\
\hline
\end{tabular}

Sumber: Diolah Data Primer, 2018 
Berdasarkan Tabel 5 jumlah biaya produksi yang harus di kelurkan oleh rumah makan usaha "Saraba" di rumah makan Stevanny di Kawasan Boulevard Kota Manado adalah Rp.10.890.519 per bulan, terdiri dari biaya bahan baku, upah tenaga kerja, biaya listrik, biaya transportasi, pajak, biaya retribusi dan biaya penyusutan.

\section{Penerimaan Usaha "Saraba" di Rumah Makan Stevanny di Kawasan Boulevard Kota Manado}

Penerimaan penjual usaha "Saraba" dirumah makan Stevanny di Kawasan Boulevard Kota Manado dihitung dari jumlah output yang dihasilkan dari hasil penjualan dengan pendapatan kotor. Untuk penghitungan penerimaan Usaha "Saraba" dirumah makan Stevanny, komponen yang dihitung adalah penjualan saraba selama satu bulan. Jumlah produksi perhari yang dihasilkan dari Usaha "Saraba" dirumah makan Stevanny adalah 55 gelas setara 27,5 liter air dengan ukuran gelas besar 500 $\mathrm{ml}$ dengan harga jual rata-rata Rp.10.000/gelas. Penerimaan tunai setiap bulan yang diperoleh penjual saraba dari awal produksi saraba adalah Rp.16.500.000 dari total penerimaan penjual saraba diperoleh dari hasil perkalian antara produksi saraba dengan harga jual yaitu Rp.10.000 per gelas.

\begin{tabular}{lr} 
Tabel 6. Penerimaan Usaha "Saraba" di Rumah Makan \\
$\begin{array}{l}\text { Stevanny di Kawasan Boulevard Kota Manado } \\
\text { Bulan September Tahun 2018 }\end{array}$ \\
\hline Uraian & Jumlah \\
\hline Harga (Rp/gelas ) & 10.000 \\
Perhari (55 gelas ) & 16.50 .000 \\
Perbulan ( 1.650 gelas) & \\
\hline Sumber: Diolah Data Primer, 2018
\end{tabular}

Tabel 6 menunjukkan bahwa penerimaan harian penjual "Saraba" di rumah makan Stevanny di Kawasan Boulevard Kota Manado sebesar 55 gelas saraba/hari atau 19.800 gelas/ tahun dengan penerimaan total Rp.16.500.000 per bulan dengan rata-rata produksi 55 gelas saraba per hari.

\section{Analisis Keuntungan Usaha "Saraba" di Rumah Makan Stevanny di Kawasan Boulevard Kota Manado Bulan September Tahun 2018}

Keuntungan total yang diperoleh usaha "Saraba" rumah makan Stevany di Kawasan Boulevard Kota Manado sangat tergantung dari jumlah penerimaan yang diterima dengan biaya yang dikeluarkan. Semakin besar penerimaan yang diperoleh dan semakin kecil biaya yang dikeluarkan, maka tingkat keuntungan semakin tinggi.
Berikut ini adalah perhitungan keuntungan usaha "Saraba" di rumah makan Stevanny di Kawasan Boulevard Kota Manado.

Tabel 7. Total Keuntungan Usaha "Saraba" Rumah Makan Stevanny Di kawasan Boulevard Kota Manado Bulan September Tahun 2018

\begin{tabular}{lr}
\hline Komponen & Jumlah \\
\hline Penerimaan & 16.500 .000 \\
Biaya Produksi & 10.890 .519 \\
Keuntungan Usaha & 5.609 .481 \\
\hline
\end{tabular}

Sumber: Diolah Data Primer, 2018

Tabel 7 menunjukkan, keuntungan penjualan "Saraba" dirumah makan Stevany di Kawasan Boulevard Kota Manado adalah Rp.5.609.481.

\section{KESIMPULAN DAN SARAN}

\section{Kesimpulan}

Berdasarkan hasil analisis dan pembahasan, dapat disimpulkan bahwa besarnya keuntungan usaha "Saraba" rumah makan Stevanny di Kawasan Boulevard Kota Manado adalah sebesar Rp.5.609.481 per bulan.

\section{Saran}

1. Pedagang dapat mengembangkan usaha dan dapat memperbanyak produksi.

2. Pedagang perlu memperhatikan keberadaannya melalui pembentukan suatu organisasi struktur usaha agar dapat memberikan manfaat khusus bagi pedagang saraba dan tenaga kerja.

3. Kepada peneliti lain diharapkan agar melakukan penelitian sejenis agar menjadi bahan perbandingan.

\section{DAFTAR PUSTAKA}

Masengi, G. 2014. Analisis Keuntungan Usaha Rumah Makan El-Shadai Di Kawasan Wisata Kuliner "Wakeke Manado" Fakultas Pertanian, Universitas Sam Ratulangi. Manado.

Tim Lentera, 2002. Khasiat dan Manfaat Jahe Merah si Rimpang Ajaib. Agro media Pustaka. Jakarta. 